\title{
Condições de vida, trabalho e acesso aos serviços de saúde em trabalhadores agrícolas e não agrícolas, Brasil, 2013
}

\author{
Living and working conditions and access to health services \\ for agricultural and non-agricultural workers, Brazil, 2013
}

Fernanda de Albuquerque Melo Nogueira (https://orcid.org/0000-0003-0331-3873) ${ }^{1}$

Celia Szwarcwald Landmann (https://orcid.org/0000-0002-7798-2095) ${ }^{1}$

Giseli Nogueira Damacena (https://orcid.org/0000-0002-7059-3353) ${ }^{1}$

${ }^{1}$ Programa de PósGraduação em Informação e Comunicação em Saúde, Instituto de Comunicação Científica e Tecnológica, Fundação Oswaldo Cruz. Av. Brasil 4036, Manguinhos. 21040-360 Rio de Janeiro RJ Brasil.

fernanda.nogueira@ inca.gov.br

\begin{abstract}
In Brazil, the growth of agribusiness to the detriment of family agriculture occurred while concealing social, environmental and human health damages. The objective was to compare living and working conditions and access to health services between agricultural and non-agricultural workers. Data from the National Health Survey (PNS) on living and working conditions, sociodemographic, economic characteristics, and access to health services from a representative sample of the employed Brazilian population were adopted. Pearson's chi-square test was used, with a significance level of 0.05, taking the complex sampling design into consideration. Agricultural workers suffered from worse living conditions, lower purchasing power, greater exposure to solar radiation and chemical agents, and a higher frequency and severity of occupational accidents compared to non-agricultural workers. The agricultural population had greater coverage of the Family Health Service and sought medical care from the Unified Health System (SUS) to treat diseases, while the non-agricultural workers sought private medical care for preventive actions. The differences found between these workers imply different patterns of illness and define specific health needs.

Key words Health surveys, Agricultural workers, Living Conditions, Working Conditions, Health Services
\end{abstract}

Resumo No Brasil, o crescimento do agronegócio em detrimento da agricultura familiar ocorreu ocultando danos sociais, ambientais e à saúde humana. Objetivou-se comparar as condições de vida, de trabalho e o acesso aos serviços de saúde, entre trabalhadores agrícolas e não agrícolas. Utilizaram-se os dados da Pesquisa Nacional de Saúde (PNS) sobre condições de vida e trabalho, características sociodemográficas, econômicas e de acesso aos serviços de saúde de uma amostra representativa da população ocupada brasileira. Empregou-se o teste qui-quadrado de Pearson, com nivel de significância de 0,05, considerando-se o desenho complexo da amostragem. Os trabalhadores agrícolas apresentaram piores condições de vida, menor poder aquisitivo, maior exposição à radiação solar e agentes químicos e maior frequência e gravidade de acidentes de trabalho em comparação aos não agrícolas. A população agrícola teve maior cobertura da ESF, buscou atendimento médico no SUS para tratar doenças, enquanto a não agrícola, buscou atendimento médico privado para ações preventivas. As diferenças encontradas entre esses trabalhadores implicam em padrões de adoecimento distintos e definem necessidades de saúde específicas.

Palavras-chave Inquéritos de saúde, Agricultores, Condições de Vida, Condições de Trabalho, Serviços de Saúde 


\section{Introdução}

A agropecuária brasileira desempenha importante papel na economia global, sendo realizada por 15 milhões de pessoas, em 5 milhões de estabelecimentos agropecuários, com área total de 350 milhões de hectares. Aproximadamente 70\% desses estabelecimentos são pequenas propriedades, com 1 a 50 hectares que praticam agricultura familiar e fornecem produtos diversificados para o mercado interno consumidor: arroz, carne de boi, café, milho, aves e suínos, leite e feijão. As médias e grandes propriedades concentram a maior parte da extensão territorial voltadas aos monocultivos de grãos, cana-de-açúcar, carne bovina, frango e porco, destinados à exportação. Esta produção representa um quarto do Produto Interno Bruto Nacional (PIB) $)^{1,2}$.

A crescente participação desses produtos no PIB, gerando superávits na balança comercial brasileira, só foi possível mediante a aprovação de leis e programas de incentivo ao crédito agrícola, em 1970, com o Plano Nacional de Defensivos Agrícolas, que condicionava a liberação do crédito à aquisição de agrotóxicos e fertilizantes, maquinários de grande porte, sementes transgênicas, entre outros. Além disso, o estabelecimento de isenções fiscais para as indústrias de agrotóxicos transnacionais criaram as condições necessárias para o Brasil, em 2008, tornar-se o maior consumidor de agrotóxicos no mundo e se destacar na exportação de commodities agrícolas (soja e milho para ração de animais, eucalipto para a produção de madeira, cana de açúcar para a produção de etanol) e outros produtos agropecuários no mercado internacional ${ }^{3}$.

No entanto, tais ganhos na economia ocorreram à custa de profundas alterações do espaço agrário, decorrentes do emprego crescente da mecanização das operações de cultivo, do uso de agrotóxicos e outros insumos químicos, resultando na hegemonia de um modelo de agricultura químico-dependente, financiada pelo capital externo, em detrimento da agricultura familiar camponesa. Essas alterações implicam na desigual distribuição, concentração e especulação fundiária, com a desapropriação de terras de pequenos agricultores e intensificação do êxodo rural, acarretando a favelização e o caos no espaço urbano. A pobreza rural, o desemprego, a violência no campo pela posse da terra; a acentuação das desigualdades sociais; a insegurança alimentar e nutricional; o uso de agrotóxicos e a utilização de sementes transgênicas, que contaminam a água, o solo e os alimentos e afetam negativa- mente à saúde humana, com casos frequentes de intoxicações por agrotóxicos, inclusive tentativas de suicídio e óbitos, são situações cotidianas vivenciadas pelos trabalhadores agropecuários ${ }^{4}$.

Portanto, a população agrícola torna-se um grupo extremamente vulnerável não só pela presença de agroquímicos que ocasionam danos severos a sua saúde, mas também por serem, em sua maioria, carentes de oferta de serviços de saúde, associada às precárias condições de traba$\mathrm{lho}^{5}$. Configura-se assim um segmento populacional marginalizado e negligenciado quanto às ações de proteção e cuidado com a saúde.

O objetivo do presente estudo foi comparar as condições de vida, de trabalho e de acesso aos serviços de saúde, entre os trabalhadores agrícolas e não agrícolas, em 2013.

\section{Materiais e métodos}

\section{Delineamento do estudo}

Trata-se de um estudo descritivo com dados da Pesquisa Nacional de Saúde (PNS), uma pesquisa de âmbito nacional e base domiciliar, realizada pela Fundação Oswaldo Cruz e pelo Ministério da Saúde, em parceria com o Instituto Brasileiro de Geografia e Estatística (IBGE).

\section{Plano amostral e população do estudo}

A PNS faz parte do Sistema Integrado de Pesquisas Domiciliares do IBGE e utiliza uma subamostra da Amostra Mestre do IBGE, com a mesma estratificação das unidades primárias de seleção (UPAs), constituídas por um ou mais setores censitários. Selecionou-se uma amostra por conglomerados em três estágios. No primeiro, em cada estrato, foi realizada a seleção das UPAs. No segundo estágio, em cada UPA, foi selecionado aleatoriamente um número fixo de domicílios. E, no terceiro estágio, em cada domicílio, foi selecionado aleatoriamente um morador adulto (de 18 anos ou mais de idade). Excluíram-se da pesquisa as áreas com características especiais e com pouca população, como aldeias indígenas, quartéis, bases militares, alojamentos, acampamentos, embarcações, penitenciárias, colônias penais, presídios, cadeias, asilos, orfanatos, conventos e hospitais ${ }^{6}$. No total, foram visitados 81.254 domicílios, destes, 69.994 estavam ocupados. Foram realizadas 64.348 entrevistas domiciliares e 60.202 com o morador selecionado. Para maiores informações sobre o desenho complexo 
da amostra verificar a publicação anterior de Souza-Júnior et al. ${ }^{6}$.

A população do estudo constituiu-se de uma amostra representativa da população ocupada na semana de referência para coleta dos dados (21 a 27 de julho de 2013), contabilizando 37.055 indivíduos.

Na PNS, a ocupação foi definida como cargo, função ou profissão exercido pela pessoa de acordo com a Classificação Brasileira de Ocupações (CBO) estabelecida pelo Ministério do Trabalho e Emprego (MTE). A CBO descreve e ordena as ocupações dentro de uma estrutura hierarquizada que possibilita reunir as informações sobre a força de trabalho, discriminando as funções, os conhecimentos, habilidades, atributos pessoais e outros requisitos necessários para o exercício da ocupação. Assim, a CBO apresenta quatro níveis hierárquicos: os grupos de base ou famílias ocupacionais (GB), os subgrupos (SG), os subgrupos principais (SGP) e os grandes grupos ocupacionais $(\mathrm{GG})^{7}$.

Os GB possuem o maior nível de desagregação. Para cada família ocupacional é descrita as grandes áreas de atividades, a formação e a experiência profissional necessária para o exercício das ocupações, e suas condições gerais para exercê-la. Já os GG formam o nível mais agregado da classificação, comportam dez conjuntos, agregados por nível de competência e similaridade nas atividades executadas.

Desde 2010, adota-se no Brasil, a classificação de ocupações para pesquisas domiciliares (COD - domiciliar), que é baseada na CBO (2002), com algumas modificações. A COD - domiciliar mantém-se idêntica à CBO (2002) no nível mais agregado - GG - e reagrupa algumas famílias ocupacionais, subgrupos e subgrupos principais, tendo em vista as dificuldades de captá-los com precisão nas pesquisas domiciliares ${ }^{8}$.

Para o presente estudo, a partir da análise da COD - domiciliar, identificou-se em cada GG, os subgrupos principais de profissionais que desenvolviam atividades relacionadas à agricultura, pecuária e afim, e em seguida, selecionaramse os grupos de base ou famílias ocupacionais para compor a categoria dos trabalhadores com ocupação agrícola. Assim, elegeram-se no GG1 (Diretores e gerentes) os dirigentes de produção agropecuária; no GG2 (Profissionais de Ciências e Intelectuais) os agrônomos e veterinários; no GG3 (Técnicos e profissionais de nível médio) os técnicos agropecuários e técnicos florestais; no GG6 (Trabalhadores qualificados da agropecuária, florestais, da caça e da pesca) todas as famílias ocupacionais; no GG7 (Trabalhadores qualificados, operários e artesão da construção, das artes mecânicas e outros ofícios) os fumigadores e outros controladores de pragas e ervas daninhas; no GG8 (Operadores de instalações e máquinas e montadores) os operadores de máquinas agrícolas e florestais móveis; e no GG9 (Ocupações elementares) os trabalhadores elementares da agricultura, pecuária e florestais. Não foram identificadas ocupações agrícolas ou relacionadas à agropecuária e afins nos GG 4 (Trabalhadores de apoio administrativo) e GG5 (Trabalhadores dos serviços, vendedores dos comércios e mercados profissionais). Todos os outros trabalhadores restantes foram classificados como trabalhadores com ocupação não agrícola. O Quadro 1 apresenta a CBO e a COD domiciliar e os subgrupos ocupacionais selecionados para o estudo.

\section{Variáveis do estudo}

1- Condições de vida: área geográfica (rural/ urbana), macrorregião (Norte, Nordeste, Sul, Sudeste, Centro-Oeste), formas de abastecimento de água (rede geral, poço/nascente fora ou dentro da propriedade, carro pipa, água de chuva armazenada em cisterna ou de outro modo, outro), tipo de escoadouro dos banheiros ou sanitários (rede geral, fossa séptica/rudimentar, vala, direto para rio ou lago, outro), destino dado ao lixo (coletado diretamente/caçamba pelo serviço de limpeza, queimado/enterrado na propriedade, jogado em terreno baldio, logradouro, rio, lago ou mar, outro), origem da energia elétrica no domicílio (rede geral, outra (solar, eólica, gerador), não tem energia elétrica).

2- Sociodemográficas e econômicas: sexo (masculino/feminino), faixa etária (18-39 anos, 40-59 anos e 60 anos ou mais), cor (branco, pardo e negro), escolaridade (curso mais elevado que frequentou anteriormente), rendimento proveniente do trabalho bruto (em salários mínimos), critério de classificação econômica Brasil (CCEB) adaptado9. O CCEB é um índice utilizado para estimar o poder de compra das famílias brasileiras considerando a quantidade de bens no domicílio, a presença de doméstica mensalista e o grau de escolaridade do chefe da família. Há um sistema de pontos em que são atribuídas maiores pontuações àqueles com bens de maior valor e maior nível de instrução do chefe da família. A soma desses pontos é agregada em intervalos para definir categorias de classe econômica: D/E (0-13 pontos); C (14-23 pontos); A/B (24-50 pontos). 
Quadro 1. Classificação Brasileira de Ocupações (CBO) e Classificação Brasileiras de Ocupações para Pesquisa Domiciliar (COD - Domiciliar).

\begin{tabular}{|c|c|c|c|c|}
\hline \multirow{2}{*}{$\begin{array}{l}\text { Grandes } \\
\text { Grupos }\end{array}$} & \multirow[b]{2}{*}{ CBO 2002} & \multirow{2}{*}{$\begin{array}{l}\text { COD - } \\
\text { domiciliar }\end{array}$} & \multicolumn{2}{|r|}{ Subgrupos ocupacionais } \\
\hline & & & $\begin{array}{c}\text { Ocupações } \\
\text { agrícolas }\end{array}$ & Ocupações não agrícolas \\
\hline 0 & $\begin{array}{l}\text { Membros } \\
\text { das Forças } \\
\text { Armadas, } \\
\text { policiais e } \\
\text { bombeiros } \\
\text { militares }\end{array}$ & $\begin{array}{l}\text { Membros } \\
\text { das Forças } \\
\text { Armadas, } \\
\text { policiais e } \\
\text { bombeiros } \\
\text { militares }\end{array}$ & - & $\begin{array}{l}\text { Membros das forças armadas, oficiais e } \\
\text { praças da polícia militar, oficiais e praças de } \\
\text { bombeiro militar }\end{array}$ \\
\hline 1 & $\begin{array}{l}\text { Membros } \\
\text { superiores do } \\
\text { poder público, } \\
\text { dirigentes de } \\
\text { organizações de } \\
\text { interesse público, } \\
\text { de empresas e } \\
\text { gerentes }\end{array}$ & $\begin{array}{l}\text { Diretores e } \\
\text { gerentes }\end{array}$ & $\begin{array}{l}\text { Dirigentes } \\
\text { de produção } \\
\text { agropecuária, } \\
\text { silvicultura, } \\
\text { aquicultura e pesca }\end{array}$ & $\begin{array}{l}\text { Diretores executivos, dirigentes da } \\
\text { administração pública, e membros do } \\
\text { poder executivo e legislativo; dirigentes } \\
\text { administrativos e comerciais, da indústria } \\
\text { de transformação, mineração, construção } \\
\text { e distribuição; de serviços de tecnologia da } \\
\text { informação e comunicações; de serviços } \\
\text { profissionais, hotéis, restaurantes, comércio } \\
\text { e serviços }\end{array}$ \\
\hline 2 & $\begin{array}{l}\text { Profissionais } \\
\text { das Ciências e } \\
\text { das Artes }\end{array}$ & $\begin{array}{l}\text { Profissionais } \\
\text { de Ciências e } \\
\text { Intelectuais }\end{array}$ & $\begin{array}{l}\text { Agrônomos e afins, } \\
\text { veterinários }\end{array}$ & $\begin{array}{l}\text { Profissionais das ciências e da engenharia, } \\
\text { da biologia, de saúde, do ensino, da } \\
\text { tecnologia da informação e comunicação } \\
\text { das ciências sociais, culturais e do } \\
\text { direito; especialistas em organização da } \\
\text { administração pública de empresa }\end{array}$ \\
\hline 3 & $\begin{array}{l}\text { Técnicos de } \\
\text { nível médio }\end{array}$ & $\begin{array}{l}\text { Técnicos e } \\
\text { profissionais } \\
\text { de nível médio }\end{array}$ & $\begin{array}{l}\text { Técnicos } \\
\text { agropecuários e } \\
\text { técnicos florestais }\end{array}$ & $\begin{array}{l}\text { Profissionais de nível médio e técnicos das } \\
\text { Ciências da engenharia, biologia (exclusive } \\
\text { da medicina), técnicos e controladores } \\
\text { da navegação marítima e aeronáutica, } \\
\text { profissionais de nível médio da saúde e afins, } \\
\text { de operações financeiras e administrativas, } \\
\text { de serviços jurídicos, sociais, culturais } \\
\text { e religiosos, técnicos em operações de } \\
\text { tecnologia da informação e das comunicações }\end{array}$ \\
\hline 4 & $\begin{array}{l}\text { Trabalhadores } \\
\text { de serviço } \\
\text { administrativo }\end{array}$ & $\begin{array}{l}\text { Trabalhadores } \\
\text { de apoio } \\
\text { administrativo }\end{array}$ & - & $\begin{array}{l}\text { Escrituários, trabalhadores de atendimento } \\
\text { ao público, trabalhadores de cálculos } \\
\text { numéricos e encarregados do registro de } \\
\text { materiais, outros trabalhadores de apoio } \\
\text { administrativo }\end{array}$ \\
\hline 5 & $\begin{array}{l}\text { Trabalhadores } \\
\text { dos serviços, } \\
\text { vendedores do } \\
\text { comércio em } \\
\text { lojas e mercados }\end{array}$ & $\begin{array}{l}\text { Trabalhadores } \\
\text { dos serviços, } \\
\text { vendedores } \\
\text { dos comércios } \\
\text { e mercados } \\
\text { profissionais }\end{array}$ & - & $\begin{array}{l}\text { Trabalhadores dos serviços pessoais, } \\
\text { vendedores, trabalhadores de cuidados } \\
\text { pessoais, trabalhadores de proteção e } \\
\text { segurança }\end{array}$ \\
\hline 6 & $\begin{array}{l}\text { Trabalhadores } \\
\text { agropecuários, } \\
\text { florestais e da } \\
\text { pesca }\end{array}$ & $\begin{array}{l}\text { Trabalhadores } \\
\text { qualificados da } \\
\text { agropecuária, } \\
\text { florestais, da } \\
\text { caça e da pesca }\end{array}$ & $\begin{array}{l}\text { Agricultores e } \\
\text { trabalhadores } \\
\text { da agricultura, } \\
\text { da pecuária, } \\
\text { de exploração } \\
\text { agropecuária mista, } \\
\text { Trabalhadores } \\
\text { florestais e afins, } \\
\text { pescadores, } \\
\text { caçadores e } \\
\text { trabalhadores da } \\
\text { aquicultura }\end{array}$ & - \\
\hline
\end{tabular}


Quadro 1. Classificação Brasileira de Ocupações (CBO) e Classificação Brasileiras de Ocupações para Pesquisa Domiciliar (COD - Domiciliar).

\begin{tabular}{|c|c|c|c|c|}
\hline \multirow{2}{*}{$\begin{array}{c}\text { Grandes } \\
\text { Grupos }\end{array}$} & \multirow[b]{2}{*}{ CBO 2002} & \multirow{2}{*}{$\begin{array}{c}\text { COD - } \\
\text { domiciliar }\end{array}$} & \multicolumn{2}{|r|}{ Subgrupos ocupacionais } \\
\hline & & & $\begin{array}{l}\text { Ocupações } \\
\text { agrícolas }\end{array}$ & Ocupações não agrícolas \\
\hline 7 & $\begin{array}{l}\text { Trabalhadores } \\
\text { da produção de } \\
\text { bens e serviços } \\
\text { industriais }\end{array}$ & $\begin{array}{l}\text { Trabalhadores } \\
\text { qualificados, } \\
\text { operários e } \\
\text { artesão da } \\
\text { construção, } \\
\text { das artes } \\
\text { mecânicas e } \\
\text { outros ofícios }\end{array}$ & $\begin{array}{l}\text { Fumigadores } \\
\text { e outros } \\
\text { controladores de } \\
\text { pragas e ervas } \\
\text { daninhas }\end{array}$ & $\begin{array}{l}\text { Trabalhadores e operários da construção } \\
\text { exclusive eletricistas; da metalurgia, da } \\
\text { construção mecânica e afins; artesãos e } \\
\text { operários das artes gráficas; trabalhadores } \\
\text { especializados em eletricidade e eletrônica; } \\
\text { operários e oficiais de processamento, } \\
\text { alimentos da madeira, da confecção e } \\
\text { afins; outros trabalhadores qualificados e } \\
\text { operários da indústria e do artesanato }\end{array}$ \\
\hline 8 & $\begin{array}{l}\text { Trabalhadores } \\
\text { da produção de } \\
\text { bens industriais }\end{array}$ & $\begin{array}{l}\text { Operadores } \\
\text { de instalações } \\
\text { e máquinas e } \\
\text { montadores }\end{array}$ & $\begin{array}{l}\text { Operadores de } \\
\text { máquinas agrícolas } \\
\text { e florestais móveis }\end{array}$ & $\begin{array}{l}\text { Operadores de instalações fixas e de } \\
\text { máquinas; montadores; maquinistas } \\
\text { de locomotivas e afins; condutores de } \\
\text { automóveis, caminhonetes e motocicletas; } \\
\text { condutores de caminhões pesados e ônibus; } \\
\text { operadores de máquinas de movimentação } \\
\text { de terras e afins, de guindastes, gruas, } \\
\text { aparatos de elevação e afins, e de } \\
\text { empilhadeiras }\end{array}$ \\
\hline 9 & $\begin{array}{l}\text { Trabalhadores } \\
\text { em serviços } \\
\text { de reparação e } \\
\text { manutenção }\end{array}$ & $\begin{array}{l}\text { Ocupações } \\
\text { elementares }\end{array}$ & $\begin{array}{l}\text { Trabalhadores } \\
\text { elementares da } \\
\text { agropecuária, da } \\
\text { pesca e florestais }\end{array}$ & $\begin{array}{l}\text { Trabalhadores domésticos e de limpeza } \\
\text { do interior de edifícios, trabalhadores } \\
\text { elementares da mineração, da construção, } \\
\text { da indústria da transformação e do } \\
\text { transporte; ajudantes de preparação de } \\
\text { alimentos, trabalhadores ambulantes dos } \\
\text { serviços e afins, coletores de lixo e outras } \\
\text { ocupações elementares }\end{array}$ \\
\hline
\end{tabular}

Fonte: Adaptado de $\mathrm{IBGE}^{8}$.

3- Ocupacionais: ocupação (agrícola/não agrícola), exposições ocupacionais ( $\operatorname{sim} /$ não), tempo de trabalho (até 15 anos, 16-30 anos, acima de 30 anos), local de trabalho (fechado, aberto e ambos), trabalho noturno ( $\operatorname{sim} /$ não), vínculo empregatício (trabalhador doméstico, do setor público/militar, do setor privado, por conta própria, não remunerado), acidentes de trabalho nos últimos 12 meses ( $\operatorname{sim} /$ não), parou de realizar atividades habituais decorrentes do acidente de trabalho ( $\operatorname{sim} /$ não), necessidade de internação por $24 \mathrm{~h}$ ou mais decorrente do acidente de trabalho ( $\operatorname{sim} /$ não), presença de sequela ou incapacidade decorrente do acidente de trabalho ( $\operatorname{sim} /$ não).

4- Cobertura, uso e acesso aos serviços de saúde: cadastro do domicílio na Estratégia de Saúde da Família (ESF) (sim/não), frequência de visita ao domicílio do agente comunitário de saúde (ACS) ou da ESF (mensal, a cada 2 meses, 2-4 meses, uma vez, nunca), frequência de visita ao domicílio do agente de controle de endemia
(ACE) (mensal, a cada 2 meses, 2-4 meses, uma vez, nunca), possui plano de saúde ( $\operatorname{sim} /$ não), última vez que procurou atendimento médico (há 1 ano, mais de 1 ano, nunca foi) e motivo pelo qual procurou o atendimento médico (doença/acidentes/lesão, acompanhamento médico/ exames, pré-natal, outro), local onde procurou o $1^{\mathrm{o}}$ atendimento médico (unidades públicas, unidades privadas, outros), foi atendido na $1^{\mathrm{a}}$ vez quando procurou o atendimento ( $\operatorname{sim} /$ não), local onde fica o serviço de saúde que obteve o atendimento médico (na mesma cidade onde mora, outra cidade).

\section{Análise estatística}

Utilizou-se o software estatístico Statistical Package for the Social Sciences (SPSS) versão 21. Calcularam-se as prevalências e seus intervalos de confiança para cada variável. Empregou-se o teste qui-quadrado de Pearson, com nível de significância de 0,05 , considerando o desenho 
complexo da amostragem, por meio do comando estatístico complex sample.

\section{Questões éticas}

A pesquisa foi aprovada em junho de 2013 pela Comissão Nacional de Ética em Pesquisa (CONEP). O trabalho de campo ocorreu entre agosto de 2013 e fevereiro de 2014.

\section{Resultados}

Participaram do estudo 37.055 trabalhadores, sendo 3.755 indivíduos com ocupação agrícola e 33.300 com ocupações não agrícolas. A Tabela 1 apresenta características ambientais e de condições de vida. Os trabalhadores com ocupação agrícola, quando comparados aos de não agrícola, são, em maior proporção de áreas rurais $(66,3 \%$ vs $6,3 \%)$, da região Nordeste $(35,4 \%$ vs $23,6 \%)$, possuem como principal fonte de abastecimento de água poço ou nascente dentro ou fora da propriedade $(43,9 \%$ vs $8,7 \%)$, utilizam como principal forma de escoadouro dos banheiros fossa séptica ou rudimentar (70,5\% vs 29,3\%) e tem a prática de queimar ou enterrar o lixo na propriedade $(49,2 \%$ vs $3,6 \%)$. A cobertura de energia elétrica pela rede geral é elevada, acima de $95 \%$ nos dois grupos de trabalhadores.

A Tabela 2 mostra o perfil sociodemográfico e econômico por ocupação dos participantes. Comparando-se à população agrícola com a não agrícola, verificou-se maior proporção de homens em ambas as ocupações, com maior percentual nas ocupações agrícolas $(78,2 \%$ vs $54,8 \%$ ), maior prevalência de idosos em trabalhadores agrícolas $(13,2 \%$ vs $5,9 \%)$, de pardos $(48,1 \%$ vs $41,0 \%)$, de trabalhadores sem instrução ou com fundamental incompleto $(70,6 \% v s$ $25,5 \%$ ), de rendimento bruto mensal menor que um salário mínimo por mês, abaixo $\mathrm{R} \$ 678,00$ (53,0\% vs 15,6\%) e de indivíduos classificados na classe D ou E (54,1\% vs 15\%).

Em relação às características do trabalho, ao confrontar trabalhadores agrícolas com não agrícolas (Tabela 3), os primeiros apresentaram: menor percentual na categoria de até 15 anos de permanência no trabalho $(56,5 \%$ vs $83,0 \%)$, maior percentual de indivíduos que trabalham em ambientes abertos (87,1\% vs $21,4 \%)$, menor proporção de trabalhadores no turno da noite (3,5\% vs 16,2\%), maiores prevalências de exposição à radiação solar (84,7\% vs 22,2\%) e ao manuseio de agentes químicos (25,3\% vs 17,4\%) e menores prevalências de exposição a barulho intenso $(16,3 \%$ vs $34,3 \%)$ e atividades que levam ao nervosismo (17,2\% vs 37,6\%), maiores prevalências de trabalhadores autônomos ou empregadores $(56,5 \%$ vs $26 \%)$, maior percentual de acidentes de trabalho $(5,1 \%$ vs $2,8 \%)$ e maior gravidade dos mesmos nesse grupo: $37,7 \%$ com limitações das atividades habituais, $8,7 \%$ com internações por pelo menos $24 \mathrm{~h}$ e $18,1 \%$ com sequelas.

A Tabela 4 aborda a cobertura, uso e acesso aos serviços de saúde. A população agrícola em relação a não agrícola apresentou maior proporção de domicílios cadastrados na ESF $(69,5 \%$ vs $50,8 \%)$, de visitas mensais de ACS ou agente da ESF $(60,2 \%$ vs $42, \%)$, de nunca terem recebido visita do ACE (50\% vs 28,7\%), menor percentual de cobertura de plano de saúde privado $(8,7 \%$ vs $28,7 \%$ ), de ter consultado médico pela última vez há um ano (59,8\% vs 72,3\%), maior prevalência de consulta médica por motivo de doença/ acidente ou lesão (56,6\% vs 44,2\%), de buscarem atendimento médico no SUS $(73,5 \%$ vs $48,4 \%)$ e de receberem atendimento médico fora da cidade onde moram (21,2\% vs $12,3 \%)$. Em ambas as populações a prevalência de ter sido atendido na $1^{\text {a }}$ vez que procurou atendimento foi elevada, maior que $95 \%$.

\section{Discussão}

O presente estudo revelou diferenças importantes quanto às condições de vida, de trabalho, uso, cobertura e acesso aos serviços de saúde entre trabalhadores agrícolas e não agrícolas.

Houve maior proporção de trabalhadores agrícolas nas áreas rurais do País, com maior prevalência no Nordeste, local onde a agricultura apresenta-se como importante atividade econômica para a região, com o predomínio do agronegócio, como o Pólo Fruticultor destinado a produção de frutas para a exportação em Pernambuco (Petrolina) Bahia (Juazeiro), Ceará (região do Baixo Jaguaribe), Rio Grande do Norte (Vale do Açu $)^{3,10}$; os monocultivos de cana- deaçúcar, em Alagoas, Pernambuco e Paraíba, e a monocultura de grãos, na região de MATOPIBA (Maranhão, Tocantins, Piauí e Bahia), entre outras culturas ${ }^{2}$. Já os trabalhadores não agrícolas concentraram-se nas áreas urbanas e no Sudeste, a macrorregião mais industrializada do Brasil.

Quanto às condições de vida, os trabalhadores agrícolas apresentaram os piores indicadores de abastecimento de água, saneamento básico e coleta de lixo. Resultados semelhantes foram en- 
Tabela 1. Características ambientais e relacionadas às condições de vida dos trabalhadores brasileiros por tipo de ocupação. Brasil, 2013.

\begin{tabular}{|c|c|c|c|c|c|c|c|c|c|c|}
\hline \multirow[t]{2}{*}{ Variáveis } & \multicolumn{3}{|c|}{$\begin{array}{l}\text { Total de trabalhadores } \\
\qquad(\mathrm{n}=37.055)\end{array}$} & \multicolumn{3}{|c|}{$\begin{array}{c}\text { Trabalhadores } \\
\text { agrícolas } \\
(\mathbf{n}=3.755) \\
\end{array}$} & \multicolumn{3}{|c|}{$\begin{array}{c}\text { Trabalhadores não } \\
\text { agrícolas } \\
(\mathbf{n}=33.300)\end{array}$} & \multirow[t]{2}{*}{$\mathbf{p}$} \\
\hline & $\mathbf{n}$ & $\%$ & IC95\% & $\mathbf{n}$ & $\%$ & IC95\% & $\mathbf{n}$ & $\%$ & IC95\% & \\
\hline Características Ambientais & & & & & & & & & & $<0,001$ \\
\hline \multicolumn{11}{|l|}{ Área Geográfica } \\
\hline Urbano & 32.472 & 87,6 & $87,1-88,2$ & 1.266 & 33,7 & $30,3-37,3$ & 31.206 & 93,7 & $93,2-94,2$ & \\
\hline Rural & 4.583 & 12,4 & $11,8-12,9$ & 2.489 & 66,3 & $62,7-69,7$ & 2.094 & 6,3 & $5,8-6,8$ & \\
\hline Macrorregião & & & & & & & & & & $<0,001$ \\
\hline Norte & 2.694 & 7,3 & $7,0-7,6$ & 387 & 10,3 & $8,9-12,0$ & 2.307 & 6,9 & $6,6-7,2$ & \\
\hline Nordeste & 9.181 & 24,8 & $24,0-25,5$ & 1.331 & 35,4 & $32,6-38,4$ & 7.850 & 23,6 & $22,8-24,4$ & \\
\hline Sudeste & 16.284 & 43,9 & $43,0-44,9$ & 1.035 & 27,6 & $24,2-31,2$ & 15.249 & 45,8 & $44,8-46,8$ & \\
\hline Sul & 5.966 & 16,1 & $15,5-16,7$ & 771 & 20,5 & $17,9-23,4$ & 5.195 & 15,6 & $15,0-16,2$ & \\
\hline Centro-Oeste & 2.930 & 7,9 & $7,6-8,2$ & 231 & 6,2 & $5,3-7,2$ & 2.699 & 8,1 & $7,8-8,4$ & \\
\hline \multicolumn{11}{|c|}{ Características relacionadas às condições de vida } \\
\hline \multicolumn{10}{|c|}{ Principal forma de abastecimento de água } & $<0,001$ \\
\hline Rede geral & 31.581 & 85,2 & $84,6-86$ & 1.610 & 42,9 & $39,3-46,5$ & 29.971 & 90,0 & $89,2-90,7$ & \\
\hline $\begin{array}{l}\text { Poço/nascente dentro } \\
\text { ou fora da propriedade }\end{array}$ & 4.530 & 12,2 & $11,5-13$ & 1.649 & 43,9 & $40,6-47,3$ & 2.881 & 8,7 & $8,0-9,4$ & \\
\hline Carro pipa & 290 & 0,8 & $0,6-1,1$ & 118 & 3,1 & $2,3-4,3$ & 172 & 0,5 & $0,3-0,8$ & \\
\hline $\begin{array}{l}\text { Água de chuva } \\
\text { armazenada em cisterna } \\
\text { ou de outro modo }\end{array}$ & 181 & 0,5 & $0,3-0,7$ & 113 & 3,0 & $2,1-4,4$ & 68 & 0,2 & $0,1-0,3$ & \\
\hline $\begin{array}{l}\text { Outra (rios, lago, } \\
\text { igarapés) }\end{array}$ & 473 & 1,3 & $1,0-1,6$ & 265 & 7,0 & $5,6-7,9$ & 208 & 0,6 & $0,5-0,8$ & \\
\hline \multicolumn{10}{|c|}{ Escoadouro dos banheiros ou sanitários } & $<0,001$ \\
\hline Rede geral & 23.142 & 64,0 & $62,7-65,2$ & 722 & 22,0 & $18,4-26,1$ & 22.420 & 68,2 & $66,9-69,4$ & \\
\hline Fossa séptica/rudimentar & 11.960 & 33,1 & $31,9-34,3$ & 2.310 & 70,5 & $66,4-74,3$ & 9.650 & 29,3 & $28,1-30,3$ & \\
\hline Vala & 414 & 1,1 & $1,0-1,4$ & 106 & 3,2 & $2,4-4,3$ & 308 & 0,9 & $0,8-1,2$ & \\
\hline Direto para rio ou lago & 565 & 1,6 & $1,3-1,9$ & 110 & 3,4 & $2,1-5,2$ & 455 & 1,4 & $1,1-1,7$ & \\
\hline Outra & 79 & 0,2 & $0,2-0,3$ & 28 & 0,9 & $0,5-1,4$ & 51 & 0,2 & $0,1-0,2$ & \\
\hline \multicolumn{11}{|l|}{ Destino dado ao lixo } \\
\hline $\begin{array}{l}\text { Coletado diretamente } \\
\text { ou em caçamba pelo } \\
\text { serviço de limpeza }\end{array}$ & 33.514 & 90,4 & $89,8-91,1$ & 1.705 & 45,4 & $41,8-49,0$ & 31.809 & 95,5 & $95,0-96,0$ & $<0,001$ \\
\hline $\begin{array}{l}\text { É queimado ou enterrado } \\
\text { na propriedade }\end{array}$ & 3.063 & 8,3 & $7,7-8,9$ & 1.848 & 49,2 & $45,7-52,8$ & 1.215 & 3,6 & $3,2-4,1$ & \\
\hline $\begin{array}{l}\text { Jogado em terreno } \\
\text { baldio, lougradouro, rio, } \\
\text { lago ou mar }\end{array}$ & 367 & 1,0 & $0,8-1,2$ & 168 & 4,5 & $3,2-6,2$ & 199 & 0,6 & $0,5-0,7$ & \\
\hline Outro & 111 & 0,3 & $0,2-0,4$ & 34 & 0,9 & $0,6-1,3$ & 77 & 0,2 & $0,2-0,3$ & \\
\hline \multicolumn{10}{|c|}{ Origem de energia elétrica no domicílio } & $<0,001$ \\
\hline Rede geral & 36.766 & 99,2 & $99-99,4$ & 3.588 & 95,5 & $94,3-96,5$ & 33.178 & 99,6 & $99,5-99,8$ & \\
\hline $\begin{array}{l}\text { Outra origem (solar, } \\
\text { eólica, gerador) }\end{array}$ & 188 & 0,5 & $0,4-0,7$ & 95 & 2,5 & $1,7-3,7$ & 93 & 0,3 & $0,2-0,4$ & \\
\hline Não tem energia elétrica & 101 & 0,3 & $0,2-0,4$ & 72 & 1,9 & $1,4-2,6$ & 29 & 0,1 & $0,0-0,2$ & \\
\hline
\end{tabular}

Fonte: Elaborado pelas autoras a partir dos dados da Pesquisa Nacional de Saúde - Brasil, 2013.

contrados no estudo de Gomes et al. ${ }^{11}$ em uma comunidade quilombola no sudoeste da Bahia, onde $93 \%$ dos domicílios enterravam ou queimavam o lixo, $40 \%$ deles tinham como principal fonte de abastecimento de água tanque/açude/ aguada.

Em relação às características sociodemográficas e econômicas, as disparidades entre os dois 


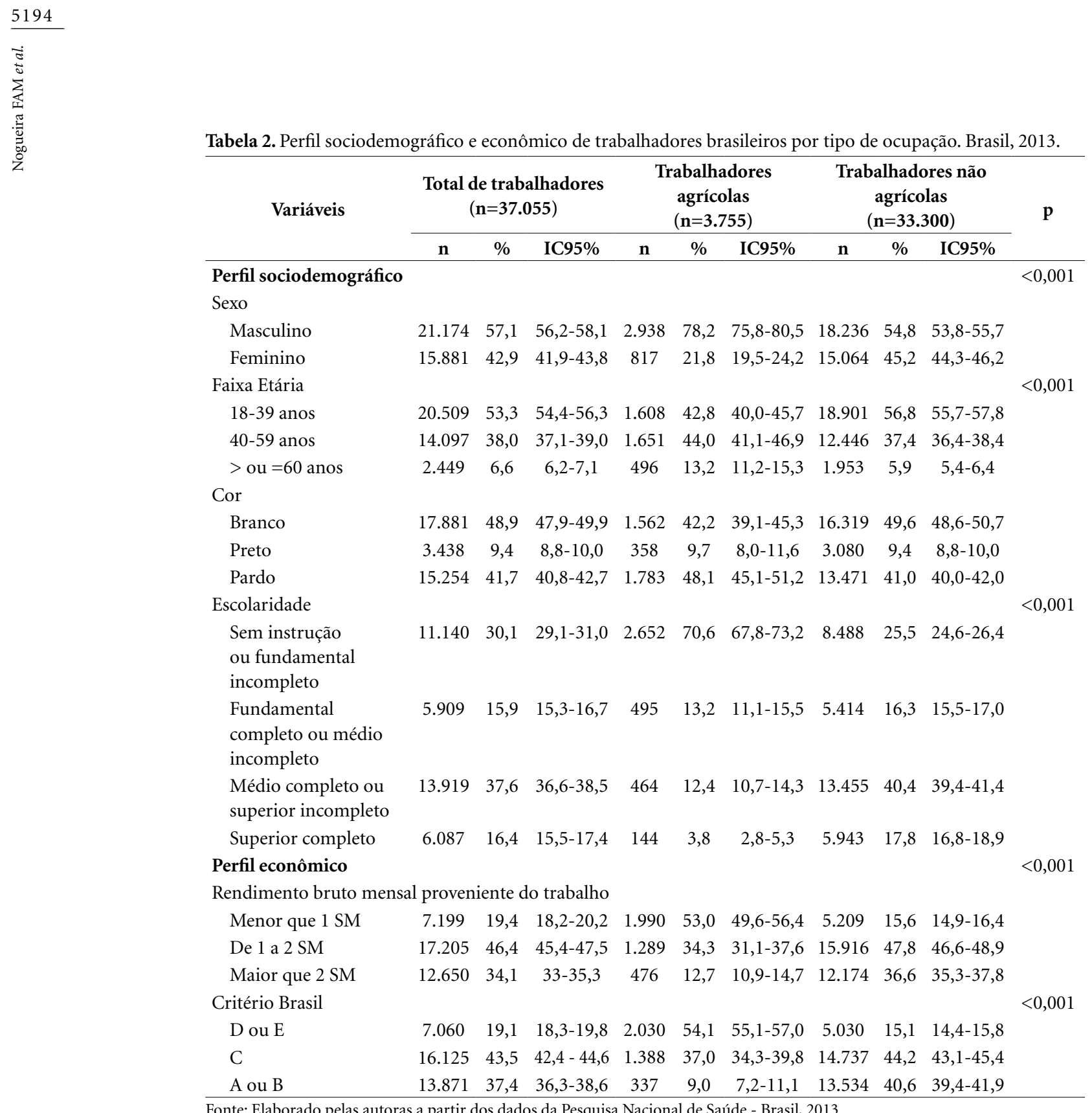

Fonte: Elaborado pelas autoras a partir dos dados da Pesquisa Nacional de Saúde - Brasil, 2013.

grupos permaneceram. Em ambos os grupos, o sexo masculino é majoritário, porém, ressalta-se que o trabalho agrícola é desenvolvido predominantemente por homens $(78,2 \%)$ indicando que no meio rural a desigualdade de gênero é ainda maior, limitando a participação das mulheres nessas atividades. Dados recentes do censo agropecuário brasileiro demonstraram que apenas $18,6 \%$ das mulheres desenvolvem atividades agrícolas nos estabelecimentos agropecuários do país ${ }^{12}$. O relatório "The role of woman in agriculture" coordenado pela Organização das Nações Unidas $^{13}$ revelou que as mulheres compreendem $43 \%$ da força de trabalho global na agricultura, realizam atividades semelhantes a dos homens, porém, sem remuneração ou com remuneração inferior.

Em relação às características sociodemográficas e econômicas, observou-se que os trabalhadores agrícolas são mais velhos, têm menor instrução e menor poder aquisitivo do que os não agrícolas. Estudos nacionais corroboram com esses achados ${ }^{12,14,15}$.

Sobre os processos de trabalho destacou-se o maior tempo de permanência no trabalho em ocupações agrícolas em comparação as não agrícolas. Um aspecto a se considerar é que 56\% dos trabalhadores agrícolas são autônomos ou empregadores, o que dificulta as licenças por aposentadoria já que o rendimento bruto provenien- 
Tabela 3. Características relacionadas ao processo de trabalho dos trabalhadores brasileiros por tipo de ocupação. Brasil, 2013.

\begin{tabular}{|c|c|c|c|c|c|c|c|c|c|c|}
\hline \multirow[t]{2}{*}{$\begin{array}{l}\text { Características dos } \\
\text { processos de trabalho }\end{array}$} & \multicolumn{3}{|c|}{$\begin{array}{l}\text { Total de trabalhadores } \\
\qquad(\mathrm{n}=37.055)\end{array}$} & \multicolumn{3}{|c|}{$\begin{array}{c}\text { Trabalhadores } \\
\text { agrícolas } \\
(\mathbf{n}=3.755) \\
\end{array}$} & \multicolumn{3}{|c|}{$\begin{array}{c}\text { Trabalhadores não } \\
\text { agrícolas } \\
(\mathbf{n}=33.300)\end{array}$} & \multirow[t]{2}{*}{$\mathbf{p}$} \\
\hline & $\mathbf{n}$ & $\%$ & IC95\% & $\mathbf{n}$ & $\%$ & IC95\% & $\mathbf{n}$ & $\%$ & IC95\% & \\
\hline Anos de permanência & & & & & & & & & & $<0,001$ \\
\hline Até 15 anos & 29.766 & 80,3 & $79,5-81,1$ & 2.121 & 56,5 & $56,3-59,6$ & 27.645 & 83,0 & $82,2-83,8$ & \\
\hline De 16 a 30 anos & 5.514 & 14,9 & $14,2-15,6$ & 872 & 23,2 & $20,9-25,7$ & 4.642 & 13,9 & $13,3-14,6$ & \\
\hline Acima de 30 anos & 1.775 & 4,8 & $4,4-5,2$ & 762 & 20,3 & $17,8-23,1$ & 1.013 & 3,0 & $2,7-3,4$ & \\
\hline Local de trabalho & & & & & & & & & & $<0,001$ \\
\hline Fechado & 19.119 & 51,6 & $50,6-52,6$ & 106 & 2,8 & $2,2-3,8$ & 19.013 & 57,1 & $56,1-58,1$ & \\
\hline Aberto & 10.382 & 28,0 & $27,1-28,9$ & 3.270 & 87,1 & $85,1-88,8$ & 7.112 & 21,4 & $20,5-22,1$ & \\
\hline Ambos & 7.554 & 20,4 & $19,6-21,2$ & 379 & 10,1 & $8,6-11,9$ & 7.175 & 21,5 & $20,7-22,4$ & \\
\hline Trabalho Noturno & 5.521 & 14,9 & $14,2-15,6$ & 133 & 3,5 & $2,5-4,9$ & 5.388 & 16,2 & $15,4-17,0$ & $<0,001$ \\
\hline \multicolumn{11}{|l|}{ Exposições ocupacionais } \\
\hline Substâncias químicas & 6.755 & 18,2 & $17,5-19,0$ & 948 & 25,3 & $22,3-28,5$ & 5.807 & 17,4 & $16,7-18,2$ & $<0,001$ \\
\hline Barulho intenso & 12.096 & 32,6 & $31,7-33,6$ & 688 & 16,3 & $16,0-20,9$ & 11.408 & 34,3 & $33,3-35,3$ & $<0,001$ \\
\hline Radiação solar & 10.557 & 28,5 & $27,6-29,4$ & 3.180 & 84,7 & $82,3-86,8$ & 7.377 & 22,2 & $21,3-23$ & $<0,001$ \\
\hline Resíduos urbanos (lixo) & 2.742 & 7,4 & $6,9-7,9$ & 139 & 3,7 & $2,6-5,2$ & 2.603 & 7,8 & $7,3-8,4$ & $<0,001$ \\
\hline $\begin{array}{l}\text { Atividades que levam ao } \\
\text { nervosismo }\end{array}$ & 13.160 & 35,5 & $34,5-36,6$ & 647 & 17,2 & $14,9-19,8$ & 12.513 & 37,6 & $36,5-38,7$ & $<0,001$ \\
\hline Material biológico & 1.786 & 4,8 & $4,4-5,2$ & 102 & 2,7 & $1,9-3,9$ & 1.684 & 5,1 & $4,6-5,5$ & 0,001 \\
\hline Poeira (pó de mármore) & 3.392 & 9,2 & $8,6-9,7$ & 126 & 3,4 & $2,5-4,5$ & 3.266 & 9,8 & $99,2-10,4$ & $<0,001$ \\
\hline Vínculo empregatício & & & & & & & & & & $<0,001$ \\
\hline $\begin{array}{l}\text { Trabalhadores } \\
\text { doméstico }\end{array}$ & 2.410 & 6,5 & $6,1-7,0$ & 20 & 0,5 & $0,3-1,0$ & 2.390 & 7,2 & $6,7-7,7$ & \\
\hline $\begin{array}{l}\text { Trabalhadores do setor } \\
\text { público/militar }\end{array}$ & 5.151 & 13,9 & $13,3-14,6$ & 42 & 1,1 & $0,7-1,7$ & 5.109 & 15,3 & $14,6-16,1$ & \\
\hline $\begin{array}{l}\text { Trabalhadores do setor } \\
\text { privado }\end{array}$ & 18.247 & 49,2 & $48,2-50,3$ & 1.270 & 33,8 & $30,5-37,3$ & 16.977 & 51,0 & $49,9-52,0$ & \\
\hline $\begin{array}{l}\text { Empregador/conta } \\
\text { própria }\end{array}$ & 10.772 & 29,1 & $28,2-30,0$ & 2.122 & 56,5 & $52,9-60,0$ & 8.650 & 26,0 & $25,1-26,8$ & \\
\hline $\begin{array}{l}\text { Trabalhador não } \\
\text { remunerado }\end{array}$ & 475 & 1,3 & $1,0-1,6$ & 301 & 8,0 & $6,0-10,6$ & 174 & 0,5 & $0,4-0,7$ & \\
\hline
\end{tabular}

Acidentes de Trabalho (considerando os acidentes de trânsito relacionados ao trabalho) nos últimos $\quad<0,001$ 12 meses

$\begin{array}{lccccccccc}\text { Sim, no trabalho } & 1.136 & 3,1 & 2,8-3,4 & 190 & 5,1 & 4-6,4 & 946 & 2,8 & 2,5-3,2 \\ \text { Sim, no trânsito } & 171 & 0,5 & 0,4-0,6 & 8 & 0,2 & 0,1-0,8 & 163 & 0,5 & 0,4-0,6 \\ \text { Não } & 35.747 & 96,5 & 96,1-96,8 & 3.557 & 94,7 & 93,4-95,8 & 32.190 & 96,7 & 96,3-97\end{array}$

Limitação das atividades habituais por acidente de trabalho mais grave

$\begin{array}{lcccccccccc}\text { Sim, no trabalho } & 519 & 18,6 & 18-23,5 & 120 & 37,7 & 30,1-46 & 399 & 20,1 & 15,6-21 & <0,001 \\ \text { Sim, no trânsito } & 658 & 26,1 & 23,2-29,3 & 83 & 26,0 & 17,8-36,4 & 575 & 26,1 & 23,1-29,4 & \\ \text { Não } & 1.344 & 53,3 & 49,9-56,7 & 116 & 36,4 & 28,8-44,5 & 1.228 & 55,8 & 52,1-59,3 & \end{array}$

Internação por $24 \mathrm{~h}$ ou mais decorrente do acidente de trabalho mais grave

$\begin{array}{lcccccccccc}\text { Sim, no trabalho } & 73 & 3,9 & 2,8-5,3 & 24 & 8,7 & 5,1-14,5 & 49 & 3,1 & 2,1-4,5 & 0,016 \\ \text { Sim, no trânsito } & 103 & 5,5 & 3,8-7,7 & 14 & 5,1 & 2,1-11,6 & 89 & 5,5 & 3,8-8,1 & \\ \text { Não } & 1.705 & 90,6 & 88,2-98,7 & 237 & 86,2 & 78,7-91,3 & 1.468 & 91,4 & 88,7-93,5 & \end{array}$

Presença de sequela ou incapacidade por acidente de trabalho mais grave

\begin{tabular}{lcccccccccc} 
Sim, no trabalho & 198 & 10,5 & $8,3-13,2$ & 50 & 18,1 & $11,6-27,1$ & 148 & 9,2 & $7,1-11,9$ & 0,013 \\
Sim, no trânsito & 209 & 11,1 & $8,8-13,9$ & 40 & 14,5 & $8,5-23,6$ & 169 & 10,5 & $8,2-13,4$ & \\
Não & 1.475 & 78,4 & $75,1-81,3$ & 186 & 67,4 & $58,7-75,1$ & 1.289 & 80,3 & $76,8-83,3$ & \\
\hline
\end{tabular}

Fonte: Elaborado pelas autoras a partir dos dados da Pesquisa Nacional de Saúde - Brasil, 2013. 
Tabela 4. Cobertura, uso e acesso aos serviços de saúde pelos trabalhadores brasileiros por tipo de ocupação. Brasil, 2013.

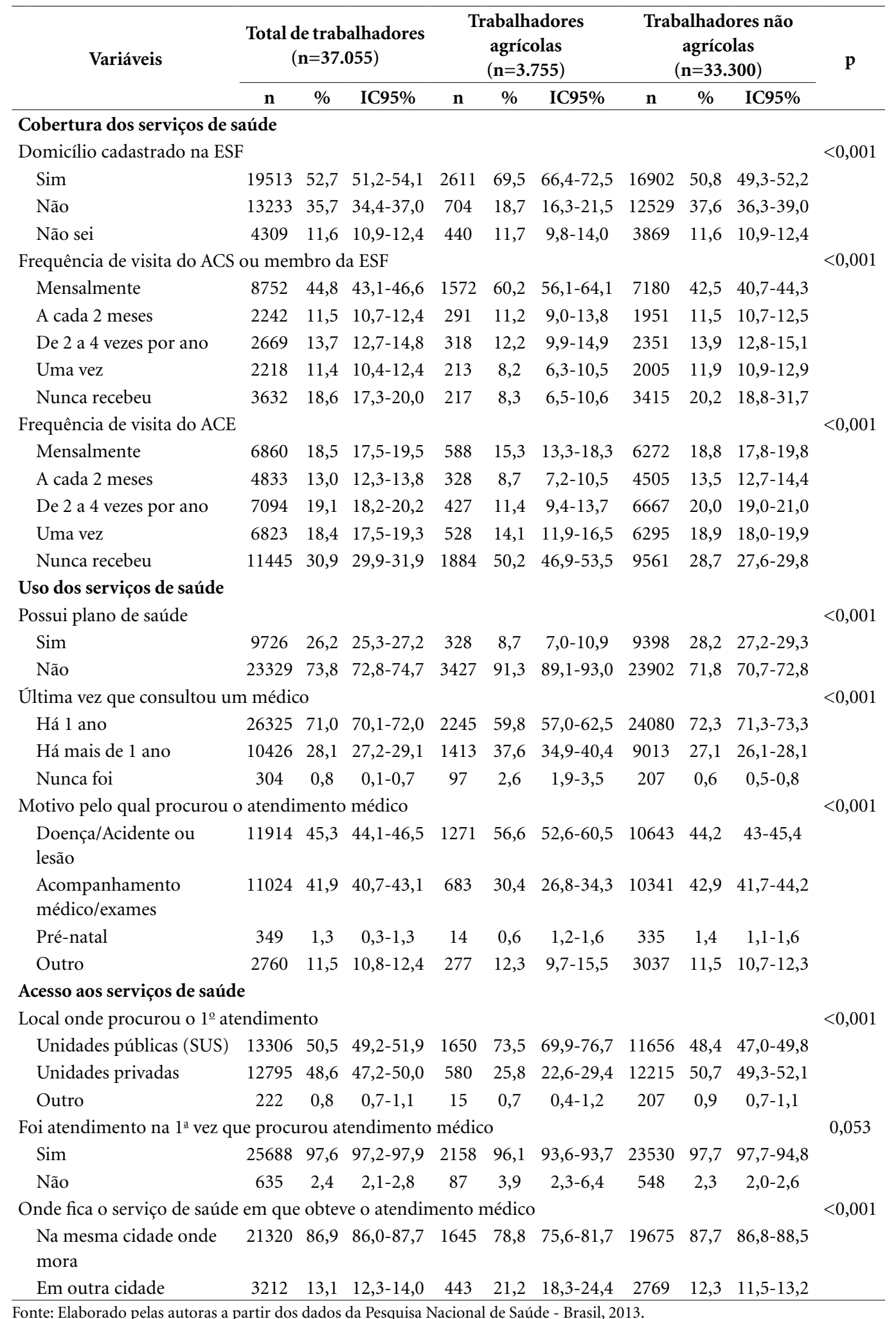


te de seu trabalho é mais baixo, obrigando-os a trabalharem por mais tempo. A Constituição de 1988 estabeleceu um sistema de aposentadoria rural, incluindo trabalhadores formais e informais, com a finalidade de universalizar o atendimento aos idosos rurais. Dentre os critérios estabelecidos destacam-se: a) equiparação de condições de acesso para homens e mulheres; b) limite de idade para aposentadoria (60 anos para homens e 55 anos para mulheres); c) introdução de um piso de aposentadoria e pensões em um salário mínimo. Esse benefício passou a ser uma importante fonte de renda, principalmente para os agricultores familiares.

Relativo ao ambiente e turno de trabalho, a maioria dos trabalhadores agrícolas, trabalhava em locais abertos e durante o dia, o que favorece a maior prevalência de exposição ao sol nessa população. Nesse mesmo grupo, também ocorreu maior prevalência de exposição a agentes químicos. É provável que a maior exposição ao manuseio de substâncias químicas decorra do uso de agroquímicos, principalmente de agrotóxicos e fertilizantes, visto que o Brasil ocupa a $1^{\text {a }}$ posição de maior consumidor de agrotóxicos no mundo (desde 2008) e a $4^{\mathrm{a}}$ de fertilizantes químicos ${ }^{16}$. Estudos internacionais revelaram prevalências de exposição aos agrotóxicos semelhantes às encontradas no nosso, na ordem de $17 \%$ na Nicarágua, $22 \%$ na Costa Rica $^{17}$ e até maiores na Guatemala $(42,2 \%)^{18}$. Devido a sua toxicidade intrínseca e capacidade de penetração e fixação nos solos, nos alimentos e nas águas e de se acumularem no organismo humano, os agrotóxicos, contaminam o meio ambiente e causam danos irreversíveis à saúde humana, especialmente em trabalhadores agrícolas, grupo de maior exposição. Câncer, doenças neurológicas, transtornos mentais, desregulação endócrina, disfunção renal e hepática, comprometimento imunológico, alterações genéticas, entre outras são doenças frequentes nesta população ${ }^{19}$. Ressalta-se que desde janeiro de 2019, o Congresso Brasileiro aprovou o registro de mais de 100 agrotóxicos, sendo 24 classificados como “altamente tóxicos" e 49 como "extremamente tóxicos”, pela Agência Nacional de Vigilância Sanitária. A liberação desenfreada desses agrotóxicos desconsiderou o banimento de alguns, em outros países, e as evidências científicas sobre os danos à saúde humana e ambiental ${ }^{20-24}$.

Outro aspecto que diverge entre essas duas populações refere-se aos acidentes de trabalho. No Brasil, o MTE reconhece o trabalho agropecuário como de alto risco para acidentes, sendo atribuído grau 3, em uma escala de 1 a 4 para classificar o risco à saúde e segurança do trabalhador da agropecuária ${ }^{25}$.

No estudo em questão, os trabalhadores agrícolas foram os mais acometidos pelos acidentes de trabalho, com as maiores prevalências de limitações das atividades habituais, de internação por pelo menos 24 horas e sequelas ou incapacidades causadas pelos acidentes. Malta et al. ${ }^{26}$ ao analisar os dados da PNS (2013) observaram que a prevalência de acidentes de trabalho para toda a população brasileira foi de $3,4 \%$ equivalente a 4,9 milhões de trabalhadores, sendo que para os trabalhadores rurais as prevalências das consequências relacionadas aos acidentes de trabalho também foram maiores, próximas às encontradas no presente estudo.

Quanto aos dados sobre a cobertura dos serviços de saúde, ressalta-se a maior proporção de domicílios de trabalhadores agrícolas cadastrados na ESF. Esse achado justifica-se pelo aumento da cobertura da atenção básica do SUS, nas áreas rurais decorrente do Programa de Saúde da Família iniciado em 1993 e sua ampliação mais acelerada em 2008, com a instituição da Política Nacional de Atenção Básica do SUS, em diversos municípios, tornando a Estratégia de Saúde da Família (ESF) uma política de Estado e um dos pilares de sustentação do Sistema Único de Saúde (SUS) ${ }^{27}$. O que é reforçado no presente estudo pela maior prevalência nas frequências mensais de vistas domiciliares de ACS e de agentes da ESF entre os trabalhadores agrícolas quando comparados aos não agrícolas. Resultados semelhantes foram encontrados na investigação de Malta et al. ${ }^{28}$ ao avaliar a cobertura da ESF no Brasil, entre 2008 e 2013, demonstrando que na área rural a cobertura é 1,4 vez maior que na área urbana e, que a ESF priorizou os domicílios em que o chefe da família apresentou menores rendimentos e escolaridade.

No entanto, no presente trabalho, a baixa prevalência encontrada de visitas de ACE entre os trabalhadores agrícolas é preocupante, pois é a população que apresentou menor escolaridade $\mathrm{e}$ possuiu as piores condições de vida, aumentando o risco de doenças infecto parasitárias (diarreia, cólera, leptospirose, leishmaniose, esquistossomose) e doenças reemergentes, como a dengue. Dentre as dificuldades encontradas pelos ACE no desenvolvimento de seu trabalho, pesquisas apontam: atuação frequente em campanhas de caráter emergencial, com ação fiscalizatória predominante sobre a educativa; dificuldades no preenchimento da ficha de cadastro; excesso de informação e orientação a serem repassadas em uma única visita; falta de transporte para reali- 
zar as visitas; domicílios fechados, vazios e não encontrados; rodízio de agentes; entre outras ${ }^{29,30}$.

No tocante aos planos de saúde, $91 \%$ dos trabalhadores agrícolas contra $72 \%$ dos não agrícolas, não possuem planos privados de saúde indicando que o SUS é o sistema mais utilizado por toda essa população. Esse dado aponta a relevância do SUS para a população brasileira, mesmo diante de limitações e dificuldades relacionadas ao acesso, à quantidade reduzida de profissionais e à qualidade dos serviços prestados, provavelmente em função do subfinanciamento crônico do sistema público de saúde e da complexa relação de interdependência pública-privada ${ }^{31}$.

Quanto ao uso dos serviços de saúde, a maior parte dos trabalhadores avaliados referiram ter consultado médico "há 1 ano atrás". Viacava et al. ${ }^{32}$, ao avaliarem o acesso e utilização dos serviços de saúde no SUS nos últimos 30 anos, constataram que para este indicador houve aumento de 54,7\% em 1998 para 71,3\% no ano de 2013, em todas as regiões brasileiras. Tal indicador expressa que o acesso aos serviços de saúde no país independente do motivo, possibilitou aumentos no nível de saúde da população e sua sobrevida ${ }^{33}$. Entretanto, o uso de serviços de saúde é fortemente influenciado pela condição social e local de residência ${ }^{34}$, pela oferta dos serviços de saúde, estado e necessidade percebida de saúde ${ }^{35}$. Os indicadores da utilização dos serviços de saúde revelam desigualdades e vulnerabilidades reais da sociedade e subsidiam o planejamento de ações em saúde ${ }^{36}$.

No presente estudo os motivos por procurar atendimento médico divergiram entre ambos os grupos, sendo o mais frequente em trabalhadores agrícolas a ocorrência de doença/lesão ou acidente e nos demais a necessidade de acompanhamento médico/realização de exames. Segundo Kassouf ${ }^{37}$, ao avaliar o acesso aos serviços de saúde no Brasil em 1998, 42,5\% da população rural procuraram atendimento médico por motivo de doença em comparação a 30,6\% da população urbana, corroborando com as observações de nosso estudo. Silva et al. ${ }^{38}$ ao analisarem os motivos de busca por atendimento médico, em adultos usuários e não usuários do SUS, entre 2003 e 2008, verificaram maior proporção de usuários do SUS que buscaram atendimento por motivo de doença enquanto os usuários não-SUS referiram maior procura para prevenção e problemas odontológicos. Esses achados sugerem que as condições socioeconômicas influenciam os motivos de procura de atendimento médico pela população.
Quanto aos locais de procura por atendimento médico, observou-se maior prevalência de procura de atendimento nas unidades de saúde do SUS pelos trabalhadores agrícolas versus os não agrícolas. Tal dado justifica-se em parte, pelo menor poder aquisitivo que impõe restrições ao acesso a serviços médicos particulares, e, pela menor distribuição da oferta de serviços de assistência à saúde da rede privada em áreas rurais, mesmo quando conveniados ao SUS, concentrando-se nas capitais, em grandes metrópoles ou centros urbanos, locais onde reside a maioria dos trabalhadores não agrícolas ${ }^{32}$.

Mais de 95\% dos trabalhadores estudados relataram ser atendidos na $1^{\text {a }}$ consulta em que buscou o atendimento médico. Achados similares foram reportados em outros estudos nacionais indicando a manutenção de uma cobertura satisfatória ${ }^{32,36,39}$.

No que diz respeito à obtenção do atendimento médico em serviços de saúde localizados fora da cidade onde moram, vale destacar a diferença encontrada na prevalência entre trabalhadores agrícolas e não agrícolas (22,2\% vs 12,3\%). Provavelmente ocorrem maiores barreiras geográficas relacionadas às distâncias a serem percorridas, dificuldades de transporte e maior concentração de pobreza ${ }^{39-41}$ em áreas rurais, onde há maior concentração de trabalhadores agrícolas.

O presente estudo apresentou como aspecto positivo e inédito analisar dados da PNS sobre a população ocupada, estratificada em agrícola e não agrícola. Os estudos que compararam esses dois grupos de trabalhadores no Brasil são muito escassos e na maioria das vezes limitam-se a comparações geográficas entre urbano e rural, não considerando variáveis relacionadas aos processos de trabalho que atuam como determinantes das condições de vida e saúde dessas populações.

Uma limitação do estudo refere-se ao fato da PNS não ser um inquérito específico para a população agrícola, não abordando assim informações sobre características das propriedades agrícolas, como: tamanho, tipos de cultivo, uso de agrotóxicos entre outras.

\section{Conclusão}

O presente estudo teve o objetivo de comparar as condições de vida, trabalho, de uso e acesso aos serviços de saúde entre os trabalhadores agrícolas e não agrícolas. Os resultados encontrados apontam que estas populações são divergentes e que as desigualdades geográficas, ambientais, sociais, 
econômicas e em relação ao acesso aos serviços de saúde existentes entre esses dois grupos são muito acentuadas. Tais diferenças provavelmente atuam sobre padrões de adoecimento distintos e definem necessidades de saúde específicas, portanto requerem recursos também diferenciados para a sua satisfação. Nesse sentido, os trabalhadores agrícolas constituem-se um grupo socialmente vulnerável, que requer políticas e programas específicos, como a Política Nacional de Saúde do Trabalhador e da Trabalhadora (2011) e a Política Nacional de Saúde Integral das Populações do Campo, da Floresta e das Águas (2013), além da proposição de outras, com a finalidade de promover melhorias nas suas condições de vida, trabalho e de saúde.

\section{Colaboradores}

FAM Nogueira, CS Landmann: concepção, delineamento, interpretação dos resultados e redação do manuscrito. GN Damacena: delineamento, análise dos dados, revisão crítica, redação e aprovação da versão final do manuscrito.

\section{Referências}

1. Instituto de Geografia e Estatística (IBGE). Censo Agropecuário - Resultados preliminares, estabelecimentos agropecuários [Internet]. Rio de Janeiro; 2018 [acessado 2019 mar 19]. Disponível em: https://censoagro2017.ibge.gov.br/templates/censo_agro/resultadosagro/pdf/estabelecimentos.pdf.

2. Brasil. Ministério da Agricultura, Pecuária e Abastecimento (MAPA). Projeções do agronegócio Brasil 2014/2015 a 2024/2025. Projeções a longo prazo [Internet]. Brasília; 2015 [acessado 2019 mar 19]. Disponível em: http://www.agricultura.gov.br/arq_editor/ PROJECOES_DO_AGRONEGOCIO_2025_WEB. pdf.

3. Carneiro FF, Rigotto RM, Augusto LGS, Friedrich K, Búrigo AC. Dossiê Abrasco: um alerta sobre os impactos doas agrotóxicos na saúde [Internet]. Rio de Janeiro, São Paulo: EPSJV/Expressão Popular; 2015 [acessado 2018 maio 10]. Disponível em: https://www. abrasco.org.br/dossieagrotoxicos/wp-content/uploads/2013/10/DossieAbrasco_2015_web.pdf.

4. Porto MF. Agrotóxicos, saúde coletiva e insustentabilidade: uma visão crítica da ecologia política. Cien Saude Colet 2007; 12(1):17-20.

5. Porto MF. Riscos, incertezas e vulnerabilidades: transgênicos e os desafios para a ciência e a governança. Politica Soc 2005; 7:77-103.

6. Souza-Júnior PRB, Freitas MPS, Antonaci GA, Szwarcwald CL. Desenho da amostra da Pesquisa Nacional de Saúde 2013. Epidemiol Serviços Saude 2015; 24(2):207-216.
7. Brasil. Ministério do Trabalho e Emprego. Classificação Brasileira de Ocupações - Códigos, Títulos e Descrições. Livro 2 [Internet]. $3^{\text {a }}$ ed. Brasília: Ministério do Trabalho e Emprego; 2010 [acessado 2018 jun 29]. Disponível em: https://drive.google.com/drive/ folders/0B3X-tDYcSc0RQmxncHhnTktMbkk?ogsrc $=32$.

8. Instituto Brasileiro de Georafia e Estatística (IBGE). Classificação de Ocupações para Pesquisas Domiciliares - COD Principais diferenças entre a COD e a CBO- Domiciliar. Rio de Janeiro: IBGE; 2010.

9. Associação Brasileira de Empresas de Pesquisa (ABEP). Critério Brasil de Classificação Econômica- Alterações na aplicação do Critério Brasil, válidas a partir de 01/01/2013 [Internet]. São Paulo; 2013 [acessado 2018 jun 29]. Disponível em: http://www.abep.org/ criterio-brasil.

10. Rigotto RM, Silva AMC, Rosa IF, Aguiar ACP. Tendências de agravos crônicos à saúde associados a agrotóxicos em região de fruticultura no Ceará, Brasil. Rev Bras Epidemiol 2013; 16(3):763-773.

11. Gomes KO, Reis EA, Guimarães MDC, Cherchiglia ML. Use of health services by quilombo communities in southwest Bahia state, Brazil. Cad Saude Publica 2013; 29(9):1829-1842.

12. Instituto Brasileiro de Geografia e Estatística (IBGE). Censo Agropecuário 2017: resultados preliminares. Rio de Janeiro: IBGE; 2017.

13. Agricultural Development Economics. The role of women in agriculture [Internet]. Roma; 2010 [acessado 2019 mar 17]. Disponível em: www.fao.org/economic/esa. 
14. Moreira JPDL, Luciano B, Oliveira BLCA, Muzi CD, Cunha CLF, Brito AS, Luiz RR. A saúde dos trabalhadores da atividade rural no Brasil. Cad Saude Publica 2015; 31(8):1698-1708.

15. Gori AM, Guimarães CR. Saúde e Mercado de Trabalho no Brasil: Diferenciais Entre Ocupados Agrícolas e Não Agrícolas. RESR 2011; 48(4):737-765.

16. Santos M, Viana M. Atlas do agronegócio - fatos e númerossobre as corporações que controlam o que comemos. Rio de Janeiro: Fundação Heinrich Böll; 2018.

17. Chaves J, Partanen T, Wesseling C, Chaverri F, Monge P, Ruepert C, Aragón A, Kogevinas M, Hogstedt C, Kauppinen T. Exposiciones laborales a agentes cancerígenos y plaguicidas en Costa Rica. Arch Prev Riesgos Labor 2005; 8(1):30-37.

18. Pan American Health Organization (PAHO). PAHO: Innovating for Health Establishing National CARcinogen EXposure (CAREX). Programs in Latin America and the Caribbean: Achievements and future directions. Washington, D.C.: PAHO; 2016.

19. World Health Organization (WHO). The Who Recommended Classification of Pesticides By Hazard and Guidelines To Classification 2009. Genebra: WHO; 2010.

20. Brasil. Casa Civil da Presidência da República. Ato $\mathrm{n}^{\circ}$ 1, de 9 de janeiro de 2019. Resumo dos pleitos de registro concedidos, de acordo com o Artigo 14 do Decreto no 4074, de 04 de janeiro de 2002. Diário Oficial da União 2019; 10 jan.

21. Brasil. Casa Civil da Presidência da República. Ato ${ }^{\circ}$ 29, de 29 de abril de 2019. Resumo dos pleitos de registro concedidos, de acordo com o Artigo 14 do Decreto $\mathrm{n}^{\circ} 4074$, de 04 de janeiro de 2002. Diário Oficial da União 2019; 30 abr.

22. Brasil. Casa Civil da Presidência da República. Ato $\mathrm{n}^{\circ}$ 24, de 9 de abril de 2019. Resumo dos pleitos de registro concedidos, de acordo com o Artigo 14 do Decreto no 4074, de 04 de janeiro de 2002. Diário Oficial da União 2019; 10 abr.

23. Brasil. Casa Civil da Presidência da República. Ato ${ }^{\circ}$ 17, de 19 de março de 2019. Resumo dos pleitos de registro concedidos, de acordo com o Artigo 14 do Decreto $\mathrm{n}^{\circ} 4074$, de 04 de janeiro de 2002. Diário Oficial da União 2019; 21 mar.

24. Brasil. Casa Civil da Presidência da República. Ato n 7, de 4 de fevereiro de 2019. Resumo dos pleitos de registro concedidos, de acordo com o Artigo 14 do Decreto $\mathrm{n}^{\circ} 4074$, de 04 de janeiro de 2002. Diário Oficial da União 2019; 11 fev.

25. Brasil. Ministério do Trabalho e Emprego. Nr 4-Serviços Especializados em Engenharia de Segurança e em Medicina do Trabalho [Internet]. Rio de Janeiro; 1996 [acessado 2019 mar 19]. Available from: http://www. trabalho.gov.br/images/Documentos/SST/NR/NR4. pdf.

26. Malta DC, Stopa SR, Silva MMA, Szwarcwald CL, Franco MS, Santos FV, Machado EL, Gómez CM. Acidentes de trabalho autorreferidos pela população adulta brasileira, segundo dados da Pesquisa Nacional de Saúde, 2013. Cien Saude Colet 2017; 22(1):169-178.

27. Brasil. Ministério da Saúde (MS). Memórias da Saúde da Família no Brasil. Brasília: MS; 2010.

28. Malta DC, Santos MAS, Stopa SR, Vieira JEB, Melo EA, Reis AAC. A Cobertura da Estratégia de Saúde da Família (ESF) no Brasil, segundo a Pesquisa Nacional de Saúde, 2013. Cien Saude Colet 2016; 21(2):327-338.
29. Souza KR, Santos MLR, Guimarães ICS, Ribeiro GS, Silva LK. Saberes e práticas sobre controle do Aedes aegypti por diferentes sujeitos sociais na cidade de Salvador, Bahia, Brasil. Cad Saude Publica 2018; 34(5):e00078017.

30. Baglini V, Favaro EA, Ferreira AC, Chiaravalloti Neto F, Mondini A, Dibo MR, Barbosa AAC, Ferraz AA, Cesarino MB. Atividades de controle do dengue na visão de seus agentes e da população atendida, São José do Rio Preto, São Paulo, Brasil. Cad Saude Publica 2005; 21(4):1142-1152.

31. Paim J, Travassos C, Almeida C, Bahia L, Macinko J. The Brazilian health system: history, advances, and challenges. Lancet 2011;377(9779):1778-1797.

32. Viacava F, Oliveira RAD, Carvalho CC, Laguardia J, Bellido JG. SUS: oferta, acesso e utilização de serviços de saúde nos últimos 30 anos. Cien Saude Colet 2018; 23(6):1751-1762.

33. Szwarcwald CL, Damacena GN, Souza Júnior PRB, Almeida WS, Malta DC. Percepção da população brasileira sobre a assistência prestada pelo médico. Brasil, 2013. Cien Saude Colet 2016; 21(2):339-350.

34. Travassos C, Oliveira EXG, Viacava F. Desigualdades geográficas e sociais no acesso aos serviços de saúde no Brasil: 1998 e 2003. Cien Saude Colet 2006; 11(4):975-986.

35. Barata RB. Acesso e uso de serviços de saúde - considerações sobre os resultados da Pesquisa de Condições de Vida 2006. São Paulo Perspect 2008; 22(2):19-29.

36. Stopa SR, Malta DC, Monteiro CN, Szwarcwald CL, Goldbaum M, Cesar CLG. Acesso e uso de serviços de saúde pela população brasileira, Pesquisa Nacional de Saúde 2013. Rev Saude Publica 2017; 51(Supl. 1):3s.

37. Kassouf AL. Acesso aos serviços de saúde nas áreas urbana e rural do Brasil. Rev Econ Sociol Rural 2005; 43(1):29-44.

38. Silva ZP, Ribeiro MCSA, Barata RB, Almeida MF. Perfil sociodemográfico e padrão de utilização dos serviços de saúde do Sistema Único de Saúde (SUS), 2003- 2008. Cien Saude Colet 2011; 16(9):3807-3816.

39. Pinheiro RS, Viacava F, Travassos C, Brito AS. Gênero, morbidade, acesso e utilização de serviços de saúde no Brasil. Cien Saude Colet 2002; 7(4):687-707.

40. Travassos C, Viacava F. Acesso e uso de serviços de saúde em idosos residentes em áreas rurais, Brasil, 1998 e 2003. Cad Saude Publica 2007; 23(10):24902502.

41. Carneiro FF, Tambellini AT, Silva JA, Haddad JPA, Búrigo AC, Sá WR, Viana FC, Bertolini VA. Saúde de famílias do Movimento dos Trabalhadores Sem Terra e de bóias-frias, Brasil, 2005. Rev Saude Publica 2008; 42(4):757-763.

Artigo apresentado em 22/07/2019

Aprovado em 04/12/2019

Versão final apresentada em 06/12/2019

Editores-chefes: Romeu Gomes, Antônio Augusto Moura da Silva 